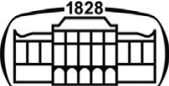

AKADÉMIAI KIADÓ

Journal of Behavioral Addictions

9 (2020) 1, 129-139

DOI:

$10.1556 / 2006.2020 .00009$

(c) 2020 The Author(s)

\section{FULL-LENGTH REPORT}

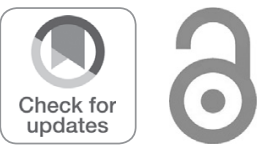

\title{
Relationship between problematic Internet use and age at initial weekly Internet use
}

\author{
HIDEKI NAKAYAMA ${ }^{1 *}$ ๑), FUMIHIKO UENO ${ }^{2}$, \\ SATOKO MIHARA ${ }^{1}$, TAKASHI KITAYUGUCHI ${ }^{1}$ and \\ SUSUMU HIGUCHI ${ }^{1}$
}

\author{
${ }^{1}$ National Hospital Organization Kurihama Medical and Addiction Center, Yokosuka, Kanagawa, \\ Japan \\ ${ }^{2}$ Department of Neuropsychiatry, Keio University School of Medicine, Shinjuku, Tokyo, Japan
}

Received: May 12, 2019 • Revised manuscript received: November 19, 2019; January 20, 2020 - Accepted: January 25, 2020 • Published online: April 7, 2020

\section{ABSTRACT}

Background and aims: An important proportion of infants and adolescents in Japan are using Internetequipped devices, including smartphones, tablets, and game consoles. However, the relationship between the risk of IA and the age at initial habitual Internet use remains unknown. We aimed to investigate this relationship among adolescents. Methods: We surveyed 1,775 subjects in seven public junior high schools in Kanagawa prefecture, Japan, in November 2017. Students were asked to complete the Young's Diagnostic Questionnaire (YDQ), which captured information regarding gender, school grade, night sleep, age at which they first started using the Internet at least once weekly, Internet usage situation, and Internet use time for purposes other than study. Data from subjects who reported experience of weekly Internet use were analyzed. Results: Junior high school students who were younger at initial weekly Internet use tended to have problematic Internet use (PIU) and to spend more time on Internet activities. In particular, initial weekly Internet use before the age of five in boys was associated with a significantly increased risk of PIU (YDQ $\geq 5$ ), with an odds ratio of 14.955 , compared with initial weekly Internet use after the age of 12. Smartphone ownership significantly increased the risk of PIU compared with no ownership among the total population and among girls. Discussion and Conclusions: Junior high school male students displayed a robust relationship between initial weekly Internet use and PIU, whereas junior high school female students displayed a particularly strong relationship between smartphone ownership and PIU. Therefore, longitudinal IA preventive education from an early age is necessary.

\section{KEYWORDS}

age at initial customary Internet use, Internet addiction, junior high school students, smartphone, Young's diagnostic questionnaire

\section{INTRODUCTION}

Most recent statistics show that in Japan, $37.2 \%$ of 2 -year-old and nearly $50 \%$ of 3-5-year-old children were using Internet-equipped devices, including smartphones, tablets, and game consoles (Cabinet office government of Japan, 2017a). Broadly, infants, children, and youth utilize the Internet for various purposes such as entertainment, retrieving information, communication, learning, and others (Cabinet office government of Japan, 2017a,b). Due to widespread use and to avoid misuse, many schools educate students on Internet usage, and some educational institutions provide lectures and learning materials via the Internet. In 2001, 49.2\% of Japanese children aged 6-12-year-used Internet services (Japan Ministry of Internal Affairs, 2001), but by 2017, this figure rose to $82.6 \%$ (Japan Ministry of Internal Affairs, 2017). Additionally, in 2017, $98.4 \%$ of 13 - to 19-year-old Japanese adolescents and 83.5\% of the total population used the Internet (Japan Ministry of Internal Affairs, 2017). The 
use of smartphones, in particular, is highly prevalent among youth. In 2017, 29.9\% of Japanese elementary school students, $58.1 \%$ of junior high school students, and $95.9 \%$ of senior high school students accessed the Internet via smartphones (Cabinet office government of Japan, 2017b).

While the Internet has enabled convenience, several negative consequences, including Internet addiction (IA), have also been identified. Young developed screening tests such as the Young's Diagnostic Questionnaire (YDQ) (Young, 1996) and Young's Internet Addiction Test (YIAT) (Young, 1998) that have been adopted by researchers investigating IA for nearly two decades. In the line of clinical disorders, certain criteria were identified for diagnosis of IA. For example, Beard and Wolf (2001) proposed diagnostic criteria for IA with reference to the Diagnostic and Statistical Manual of Mental Disorders (DSM)-IV criteria for pathological gambling. Four main components in these criteriaexcessive use, withdrawal, tolerance, and negative repercussions-were identified in YDQ (Young, 2009). However, it has been argued that the concept of IA lacks academic rigor. For example, Baggio et al. (2018) identified that IA was related to other behavioral addictions (smartphone addiction, gaming addiction, and cybersex addiction), but the latter were relatively independent constructs. Therefore, due to this connection, between IA and independent constructs, IA could be conceptualized as an "umbrella construct." Because Internet activities include various different types of activities (e.g., games, social networking services (SNS), movies, etc.), Starcevic and Aboujaoude (2017) proposed that IA should be replaced by terms that refer to specific behaviors. The diagnostic criteria for Internet Gaming Disorder (IGD), were included in the DSM-5, and the diagnostic criteria for Gaming Disorder (GD) have been proposed in the International Classification of Diseases (ICD)-11. However, an official definition and diagnostic criteria for IA remains lacking.

The usage rate of Internet among Japanese junior high school students was reported to be $95.1 \%, 74.1 \%$ for games and $68.1 \%$ for communication applications (Cabinet office government of Japan, 2017b). While some adolescents have not experienced specific Internet services (e.g., gaming, SNS, movies, etc.), there are few adolescents who have not experienced any Internet services at all. Therefore, we considered the term "IA" to be easily understood by most adolescents, rather than a specific addiction (e.g., gaming disorder, SNS addiction, etc.).

A Japanese school-based survey using the YDQ revealed that IA (YDQ $\geq 5$ ) was prevalent in $6.2 \%$ of males and $9.8 \%$ of females (Mihara et al., 2016). School-based surveys using the YIAT among adolescents in six Asian countries (China, Hong Kong, Japan, South Korea, Malaysia, and the Philippines) revealed IA (YIAT $\geq 70$ ) was prevalent in 1.2-4.9\% of adolescents (Mak et al., 2014). In their meta-analysis, Cheng and Li (2014) estimated that the global prevalence of IA was $6.0 \%$ and is a worldwide problem among youths. It was reported that IA among youth associated to sleeping disorders (Choi et al., 2009), poor academic achievement (Stavropoulos, Alexandraki, \&
Motti-Stefanidi, 2013), and worsening of psychiatric symptoms (Kawabe, Horiuchi, Ochi, Oka, \& Ueno, 2016). In Japan, treatments for IA including group and individual psychotherapy, and comorbid psychiatric disorders are provided in some medical institutions and treatment camps in some youth facilities (Sakuma et al., 2017).

Some schools provide IA-preventive education for students and their guardians, based on the findings that IA preventive education effectively reduced Internet misuse (Korkmaz \& Kiran-Esen, 2012) and number of Internetbased gamers (de Leeuw, de Bruijn, de Weert-van Oene \& Schrijvers, 2010). Longitudinal IA studies have identified Male gender, attention deficit hyperactivity symptoms, hostility symptoms (Ko, Yen, Chen, Yeh, \& Yen, 2009), low self-esteem, low family function, online game playing (Ko, Yen, \& Yen, 2007), withdrawal symptoms, and depressive/ anxiety symptoms (Cho, Sung, Shin, Lim, \& Shin, 2013) as risk factors for IA. Cross-sectional studies have reported low socio-economic status (Lee \& Kwame, 2015), family conflicts, study-related stress (Wang et al., 2011), smoking, drug abuse (Sung, Lee, Noh, Park \& Ahn, 2013), Internet gambling (Critselis et al., 2013), poor parental relationships (Tang et al., 2014), and obesity (Koyuncu, Unsal, \& Arslantas, 2014) to be IA risk factors.

Studies have suggested that early onset of substance use, particularly alcohol (Grant \& Dawson, 1997) and nicotine (Lanza \& Vasilenko, 2015) is associated with an increased risk of substance-dependence later in life. Along the same lines, younger age at first exposure to the Internet was associated with IA in adolescents or adults (Aktepe, OlgaçDündar, Soyöz, \& Sönmez, 2013; Kamal \& Mosallem, 2013; Koyuncu et al., 2014; Lee, Shin, Cho, \& Shin, 2014; Ni, Yan, Chen, \& Liu, 2009; Tsitsika et al., 2014). Though it has been noted that it is difficult for parents to prevent their children from occasionally using the Internet, it is possible for parents to prevent their children from habitual use of the Internet. This aspect has not been investigated in previous studies examining the relationship between the risk of IA and onset of habitual use of the Internet in early childhood.

This study was aimed at preventing IA in students. We investigated this relationship among junior high school students in order to help create longitudinal IA-preventive education based on risk factors from an early age.

\section{METHODS}

\section{Participants}

This survey was conducted at seven public junior high schools in a city in Kanagawa prefecture, Japan, in November 2017. Kanagawa prefecture is located near Tokyo, the capital of Japan. Kanagawa prefecture has a population of approximately nine million, and comprises several large cities. Subjects enrolled in the survey were students of all grades in seven public junior high schools $(n=2,454$ as of May 1, 2017). A total of 2,155 students participated in the survey, of whom 1,825 completed the questionnaire. We 
Table 1. Gender, school grade, bedtime, family rules on Internet use, and average duration in minutes of daily Internet use by Young's Diagnostic Questionnaire (YDQ) score

\begin{tabular}{|c|c|c|c|c|}
\hline & $\begin{array}{c}\text { Total } \\
(N=1,775)\end{array}$ & $\begin{array}{l}\text { NIU }^{\mathrm{a}} \text { group } \\
(N=1,616)\end{array}$ & $\begin{array}{l}\text { PIU }^{\mathrm{b}} \text { group } \\
(N=159)\end{array}$ & Statistics \\
\hline Gender $(/$ Total $\times 100(\%))$ & & & & $\chi^{2}=5.73, P=0.020$ \\
\hline Male & $864(100.0 \%)$ & $801(92.7 \%)$ & $63((7.3 \%)$ & \\
\hline Female & $911(100.0 \%)$ & $815(89.5 \%)$ & $96(10.5 \%)$ & \\
\hline School Grade $(/$ Total × $100(\%))$ & & & & $\chi^{2}=8.09, P=0.018$ \\
\hline 7th & $641(100.0 \%)$ & $600(93.6 \%)$ & $41(6.4 \%)$ & \\
\hline 8th & $573(100.0 \%)$ & $514(89.7 \%)$ & $59(10.3 \%)$ & \\
\hline 9th & $561(100.0 \%)$ & $502(89.5 \%)$ & $59(10.5 \%)$ & \\
\hline Bedtime on weekdays $(/$ Total $\times 100(\%))$ & & & & $\chi^{2}=53.54, P<0.001$ \\
\hline Before or at $21: 59$ hours & $152(100.0 \%)$ & $143(94.1 \%)$ & $9(5.9 \%)$ & \\
\hline 22:00-22:59 hours & $491(100.0 \%)$ & $465(94.7 \%)$ & $26(5.3 \%)$ & \\
\hline 23:00-23:59 hours & $592(100.0 \%)$ & $553(93.4 \%)$ & $39(6.6 \%)$ & \\
\hline 0:00-0:59 hours & $336(100.0 \%)$ & $288(85.7 \%)$ & $48(14.3 \%)$ & \\
\hline At or after 1:00 hours & $204(100.0 \%)$ & $167(81.9 \%)$ & $37(18.1 \%)$ & \\
\hline Bedtime on holidays $(/$ Total $\times 100(\%))$ & & & & $\chi^{2}=93.36, P<0.001$ \\
\hline Before or at $21: 59$ hours & $159(100.0 \%)$ & $151(95.0 \%)$ & $8(5.0 \%)$ & \\
\hline 22:00-22:59 hours & $447(100.0 \%)$ & $433(96.9 \%)$ & $14(3.1 \%)$ & \\
\hline 23:00-23:59 hours & $533(100.0 \%)$ & $490(91.9 \%)$ & $43(8.1 \%)$ & \\
\hline 0:00-0:59 hours & $353(100.0 \%)$ & $321(90.9 \%)$ & $32(9.1 \%)$ & \\
\hline At or after 1:00 hours & $283(100.0 \%)$ & $221(78.1 \%)$ & $62(21.9 \%)$ & \\
\hline Family rules regarding Internet use & & & & $\chi^{2}=0.67, P=0.410$ \\
\hline Yes & $1,070(100.0 \%)$ & $979(91.5 \%)$ & $91(8.5 \%)$ & \\
\hline No & $705(100.0 \%)$ & $637(90.4 \%)$ & $68(9.6 \%)$ & \\
\hline $\begin{array}{l}\text { Average minutes of daily Internet use } \\
\text { on weekdays (mean } \pm S D \text { ) }\end{array}$ & $108.9 \pm 111.9$ & $100.3 \pm 103.5$ & $196.4 \pm 150.2$ & $F=41.69, P<0.001$ \\
\hline $\begin{array}{l}\text { Average minutes of daily Internet use } \\
\text { on holidays (mean } \pm \text { SD) }\end{array}$ & $186.5 \pm 195.5$ & $168.3 \pm 173.3$ & $371.2 \pm 290.7$ & $F=92.24, \boldsymbol{P}<0.001$ \\
\hline
\end{tabular}

${ }^{a}$ NIU: Normal Internet use (YDQ score $\leq 4$ points).

${ }^{\mathrm{b}} \mathrm{PIU}$ : Problematic Internet use (YDQ score $\geq 5$ points).

analyzed 1,775 participants who experienced weekly Internet use. Of these, 50 subjects who completed the questionnaire and answered no experience of weekly Internet use were excluded, $41(82.0 \%)$ of individuals spent 0 minutes on Internet use during weekdays, $35(70.0 \%)$ spent 0 minutes on Internet during holidays, and $41(82.0 \%)$ with a YDQ score of 0 points indicating light Internet users.

\section{Procedure and assessment}

The YDQ is a self-reported scale concerning Internet addiction and consists of eight questions, with a "yes" or "no" response and scores ranging from 0 to 8 . Young proposed that respondents who answered "yes" to five or more items were addictive Internet users (Young, 1996). The YDQ has been previously used in several studies and because of the small number of items; it is an easy and feasible tool to use for the purpose outlined in this study. The Japanese version of the YDQ (Ohida et al., 2014) was back translated to avoid language bias. The Cronbach's alpha of the YDQ was 0.719 in this study, and subjects whose YDQ scores ranged from 0-4 points were classified as the Normal Internet Use (NIU) group, and the subjects whose scores ranged from 5-8 points were classified as the Problematic Internet Use (PIU) group. This questionnaire included items regarding gender, school grade, night sleep, age at which they first started using the
Internet at least once a week, Internet usage situation, Internet use time for purposes other than study and Japanese version of the YDQ (Ohida et al., 2014; Young, 1996). In November 2017, students completed the self-reported anonymous questionnaires in their classrooms by responding to the questionnaire that were then sealed in individual envelopes and submitted to their teachers. The staffs of the Board of Education unsealed the envelopes and entered the data into a database. After this survey, the authors lectured on IA-prevention measures to students and teachers in each participating school and explained the results and their implications.

\section{Statistical analysis}

A comparison of continuous data among groups by age at initial weekly Internet use was assessed with a one-way analysis of variance (ANOVA), and a post-hoc analysis between the group with initial weekly Internet use after 12 years of age and the group with initial weekly Internet use before this age was performed using Dunnett's test. The comparison of continuous data between NIU and PIU group were assessed using the Student's $t$-test. The comparison of categorical data between NIU and PIU group were assessed using a chi-square test. A multivariable logistic regression analysis was conducted to assess the relationship between PIU and independent variables among all participants, males, and females. The 
independent variables in model 1 (Table 3) were the type of Internet services used. The independent variables included in model 2 (Table 5) included gender, school grade, age at initial weekly Internet use (more than 12 years old vs. 10-11, 8-9, 67 , or less than 5 years old), ownership of a smartphone (none vs. smartphone), and family rules regarding Internet use. A $P$ value of less than 0.05 was considered statistically significant. All the statistical analyses were performed using SPSS Statistics, version 22.0 (SPSS Inc., Chicago, IL, USA).

\section{Ethics}

The study procedures were performed in accordance with the Declaration of Helsinki. The study protocol was approved by the ethics committee of the National Hospital Organization Kurihama Medical and Addiction Center and addiction preventive education committee of a city. Before surveying, the authors and teachers sent letters to the students' guardians (e.g., parents) explaining the purpose of the study, the contents of the questionnaire, the opportunity to refuse participation in the study, the protection of the students' private information, the presentation at a conference, and the publication of this study's findings. The students' teachers also relayed the information to the students. The questionnaire was anonymous, and the students' private information was protected. Subjects gave informed consent, and subject's anonymity was preserved.

\section{RESULTS}

\section{Background, bedtime, and family rules by YDQ score}

Subject demographics including gender, as well as school grade, bedtime, family rules regarding Internet use, and the average duration of daily Internet use in minutes, and subject's YDQ score are provided in Table 1. In total, 159 (9.0\%) of the participants $(n=1775)$ were classified as belonging to the PIU group; 864 (48.7\%) of the subjects were male; 641 (36.1\%) were in seventh grade; $573(32.3 \%)$ were in eighth grade; $561(31.6 \%)$ were in ninth grade; $540(30.4 \%)$ of the subjects went to bed at or after 0:00 h on weekdays; and 636 (35.8\%) of the subjects went to bed at or after $0: 00 \mathrm{~h}$ on holidays. The rate of PIU was higher among females compared to that of males, and significantly increased with school grades. Bedtime on weekdays and holidays were significantly later in the PIU group than in the NIU group. Additionally, the families of 1,071 (60.3\%) subjects had rules regarding Internet use. The subjects spent an average of $108.9 \mathrm{~min}$ on the Internet on weekdays and $186.5 \mathrm{~min}$ on the Internet on holidays. The average duration of Internet use on weekdays and holidays were significantly longer among PIU group than among NIU group.

\section{Association between type of Internet services used and risks of PIU}

The type of Internet services used by YDQ score is provided in Table 2. In male subjects, the rate of "e-mail, chat, and
Internet telephone," "blog and internet bulletin board," "SNS," "online game," and "shopping and auction" users were significantly higher in PIU group than in the NIU group. In female subjects, the rate of "blog and internet bulletin board," "SNS," "online game," "movie and music," "shopping and auction," and "other contents" users were significantly higher in PIU group than in NIU group.

Table 3 shows the association between type of Internet services used and the risk of PIU. In all subjects, "blog and internet bulletin board," "SNS," "online game," "movie and music" were associated with a significantly increased risk of PIU; "Information and news searching" were associated with a significantly decreased risk of PIU. Among males, "blog and internet bulletin board," "SNS," and "online game" were associated with a significantly increased risk of PIU. In females, "SNS," "online game," and "movie and music" were associated with a significantly increased risk of PIU, and "Information and news searching" were associated with a significantly decreased risk of PIU.

Table 2. Type of Internet services used by Young's Diagnostic Questionnaire (YDQ) score

\begin{tabular}{|c|c|c|c|}
\hline & NIU' group & PIU $^{\mathrm{b}}$ group & Statistics \\
\hline \multicolumn{4}{|l|}{ Males } \\
\hline $\begin{array}{c}\text { Information and } \\
\text { news searching }\end{array}$ & $488(60.9 \%)$ & $43(68.3 \%)$ & $\begin{array}{l}\chi^{2}=1.33 \\
P=0.283\end{array}$ \\
\hline $\begin{array}{l}\text { E-mail, chat, and } \\
\text { Internet telephone }\end{array}$ & $428(53.4 \%)$ & $42(66.7 \%)$ & $\begin{array}{l}\chi^{2}=4.12 \\
P=0.049\end{array}$ \\
\hline $\begin{array}{l}\text { Blog and internet } \\
\text { bulletin board }\end{array}$ & $74(9.2 \%)$ & $22(34.9 \%)$ & $\begin{aligned} \chi^{2} & =39.01 \\
P & <0.001\end{aligned}$ \\
\hline $\begin{array}{l}\text { Social networking } \\
\text { services }\end{array}$ & $137(17.1 \%)$ & $29(46.0 \%)$ & $\begin{aligned} \chi^{2} & =31.49 \\
P & <0.001\end{aligned}$ \\
\hline Online game & $391(48.8 \%)$ & $46(73.0 \%)$ & $\begin{aligned} \chi^{2} & =13.69, \\
P & <0.001\end{aligned}$ \\
\hline Movie and music & $613(76.5 \%)$ & $53(84.1 \%)$ & $\begin{array}{l}\chi^{2}=1.91 \\
P=0.212\end{array}$ \\
\hline Shopping and auction & $118(14.7 \%)$ & $16(25.4 \%)$ & $\begin{array}{l}\chi^{2}=5.07 \\
P=0.030\end{array}$ \\
\hline Others & $74(9.2 \%)$ & $6(9.5 \%)$ & $\begin{array}{l}\chi^{2}=0.01 \\
P=0.940\end{array}$ \\
\hline \multicolumn{4}{|l|}{ Females } \\
\hline $\begin{array}{c}\text { Information and } \\
\text { news searching }\end{array}$ & $538(66.0 \%)$ & $62(64.6 \%)$ & $\begin{array}{l}\chi^{2}=0.08 \\
P=0.820\end{array}$ \\
\hline $\begin{array}{l}\text { E-mail, chat, and } \\
\text { internet telephone }\end{array}$ & $600(73.6 \%)$ & $70(72.9 \%)$ & $\begin{aligned} \chi^{2} & =0.022 \\
P & =0.903\end{aligned}$ \\
\hline $\begin{array}{l}\text { Blog and internet } \\
\text { bulletin board }\end{array}$ & $66(8.1 \%)$ & $16(16.7 \%)$ & $\begin{array}{l}\chi^{2}=7.70 \\
P=0.012\end{array}$ \\
\hline $\begin{array}{l}\text { Social networking } \\
\text { services }\end{array}$ & $264(32.4 \%)$ & $58(60.4 \%)$ & $\begin{aligned} \chi^{2} & =29.52, \\
P & <0.001\end{aligned}$ \\
\hline Online game & $162(19.9 \%)$ & $38(39.6 \%)$ & $\begin{aligned} \chi^{2} & =19.47, \\
P & <0.001\end{aligned}$ \\
\hline Movie and music & $631(77.4 \%)$ & $88(91.7 \%)$ & $\begin{aligned} \chi^{2} & =10.48 \\
P & =0.001\end{aligned}$ \\
\hline Shopping and auction & $104(12.8 \%)$ & $24(25.0 \%)$ & $\begin{aligned} \chi^{2} & =10.65 \\
P & =0.003\end{aligned}$ \\
\hline Others & $75(9.2 \%)$ & $16(16.7 \%)$ & $\begin{array}{l}\chi^{2}=5.32 \\
P=0.029\end{array}$ \\
\hline
\end{tabular}

${ }^{a}$ NIU: Normal Internet use (YDQ score $\leq 4$ points).

${ }^{\mathrm{b}} \mathrm{PIU}$ : Problematic Internet use (YDQ score $\geq 5$ points). 
Table 3. Associations between type of Internet services used and risks of Problematic Internet use (PIU: YDQ ${ }^{\mathrm{a}}$ ) score $\geq 5$ points

\begin{tabular}{|c|c|c|c|c|c|c|c|c|c|}
\hline & \multicolumn{3}{|c|}{ Total } & \multicolumn{3}{|c|}{ Males } & \multicolumn{3}{|c|}{ Females } \\
\hline & Adjusted OR & $95 \% \mathrm{CI}$ & $P$-value & Adjusted OR & $95 \% \mathrm{CI}$ & $P$-value & Adjusted OR & $95 \% \mathrm{CI}$ & $P$-value \\
\hline \multicolumn{10}{|c|}{ Information and news searching } \\
\hline No & Reference & & & Reference & & & Reference & & \\
\hline Yes & 0.646 & $0.434-0.963$ & 0.032 & 0.699 & $0.362-1.352$ & 0.288 & 0.580 & $0.350-0.961$ & 0.034 \\
\hline \multicolumn{10}{|c|}{ E-mail, chat, and internet telephone } \\
\hline No & Reference & & & Reference & & & Reference & & \\
\hline Yes & 0.468 & $0.569-1.296$ & 0.468 & 1.133 & $0.601-2.135$ & 0.699 & 0.593 & $0.343-1.025$ & 0.061 \\
\hline \multicolumn{10}{|c|}{ Blog and internet bulletin board } \\
\hline No & Reference & & & Reference & & & Reference & & \\
\hline Yes & 1.703 & $1.064-2.726$ & 0.027 & 3.277 & $1.634-6.573$ & 0.001 & 1.077 & $0.538-2.155$ & 0.834 \\
\hline \multicolumn{10}{|c|}{ Social networking services } \\
\hline No & Reference & & & Reference & & & Reference & & \\
\hline Yes & 3.164 & $2.154-4.646$ & $<0.001$ & 2.594 & $1.337-5.034$ & 0.005 & 3.006 & $1.844-4.902$ & $<0.001$ \\
\hline \multicolumn{10}{|c|}{ Online game } \\
\hline No & Reference & & & Reference & & & Reference & & \\
\hline Yes & 1.704 & $1.197-2.428$ & 0.003 & 1.923 & $1.033-3.580$ & 0.039 & 2.092 & $1.292-3.390$ & 0.003 \\
\hline \multicolumn{10}{|c|}{ Movie and music } \\
\hline No & Reference & & & Reference & & & Reference & & \\
\hline Yes & 1.780 & $1.040-3.047$ & 0.035 & 0.968 & $0.453-2.065$ & 0.932 & 3.003 & $1.360-6.733$ & 0.007 \\
\hline \multicolumn{10}{|c|}{ Shopping and auction } \\
\hline No & Reference & & & Reference & & & Reference & & \\
\hline Yes & 1.132 & $0.732-1.750$ & 0.578 & 0.968 & $0.485-1.932$ & 0.927 & 1.339 & $0.755-2.375$ & 0.318 \\
\hline \multicolumn{10}{|c|}{ Others } \\
\hline No & Reference & & & Reference & & & Reference & & \\
\hline Yes & 0.484 & $0.717-2.021$ & 0.484 & 0.284 & $0.231-1.536$ & 0.284 & 1.714 & $0.909-3.232$ & 0.096 \\
\hline
\end{tabular}

${ }^{\text {a} Y D Q: ~ Y o u n g ' s ~ D i a g n o s t i c ~ Q u e s t i o n n a i r e . ~}$

\section{Association between Internet use and YDQ score by age at initial weekly Internet use}

The type of Internet services used by age at initial weekly Internet use is provided in Table 4. Both male and female subjects who were younger at initial weekly Internet use tended to use several types of Internet services. Figure 1 shows the average duration of daily Internet use in minutes on weekdays and holidays by age at initial weekly Internet use. The average daily duration of Internet use tended to be longer in both male and female subjects, who began using the Internet weekly at a younger age. Figure 2 shows the YDQ scores by the age at initial weekly Internet use. Both male and female subjects who were younger at initial weekly Internet use tended to have PIU.

\section{Factors associated with the risk of problematic Internet use (PIU)}

Table 5 shows the association between multiple factors (gender, school grade, initial age at weekly Internet use, ownership of a private smartphone, family rules regarding Internet use) and the risk of PIU. Females had a significantly increased risk of PIU with an odds ratio (OR) of 1.656 compared with males. Higher school grades were associated with higher ORs for PIU. Younger age at initial weekly Internet use was associated with higher ORs for PIU among males and females. Among males, initial weekly Internet use before the age of five was associated with a significantly increased risk of PIU, with an OR of 14.955, compared with initial weekly Internet use after the age of 12 . Owning a smartphone was significantly associated with an increased risk of PIU among female subjects. Family rules regarding Internet use were not significantly associated with the risk of PIU.

\section{DISCUSSION}

This cross-sectional survey investigated factors associated with an increased risk of PIU. Our results showed that female gender was associated with a significantly higher risk of PIU with an OR of 1.656 compared to male. Previous studies did not show a conclusive relationship between IA and gender. Whereas some reported that males have a higher risk for IA (Jang, Hwang, \& Choi, 2008; Ko et al., 2009; Yen et al., 2008), others reported that gender was not significantly associated with an increased risk for the occurrence of IA (Choi et al., 2009; Wang et al., 2011), and yet, others showed that the prevalence rate of IA was higher in females (Kuss, van-Rooij, Shorter, Griffiths, \& van-de Mheen, 2013; Mihara et al., 2016). We showed in this study that subjects in higher school grades displayed a significant association with PIU compared to those in lower grades. It was reported that high school students in higher school grades displayed a significant association with IA (Hao, Oh, Subramanian, Kim, \& Kawachi, 2014; Mihara et al., 2016). While our results are in concordance with previous findings, we also found that family rules regarding Internet use were not related to the participant's risk for PIU. 
Table 4. Type of Internet services used by age at initial weekly Internet use (/Total $\times 100(\%))$

\begin{tabular}{|c|c|c|c|c|c|c|}
\hline & $\leq 5$ years old & $\begin{array}{c}6 \text { or } 7 \\
\text { years old }\end{array}$ & $\begin{array}{c}8 \text { or } 9 \\
\text { years old }\end{array}$ & $\begin{array}{l}10 \text { or } 11 \\
\text { years old }\end{array}$ & $\geq 12$ years old & Statistics \\
\hline Males & $(N=54)$ & $(N=109)$ & $(N=215)$ & $(N=311)$ & $(N=175)$ & \\
\hline Information and news searching & $37(68.5 \%)$ & $76(69.7 \%)$ & $141(65.6 \%)$ & $175(56.3 \%)$ & $102(58.3 \%)$ & $\begin{aligned} \chi^{2} & =10.10 \\
\boldsymbol{P} & =0.039\end{aligned}$ \\
\hline $\begin{array}{l}\text { E-mail, chat, and internet } \\
\text { telephone }\end{array}$ & $36(66.7 \%)$ & $70(64.2 \%)$ & $121(56.3 \%)$ & $156(50.2 \%)$ & $87(49.7 \%)$ & $\begin{aligned} \chi^{2} & =11.62, \\
P & =0.020\end{aligned}$ \\
\hline Blog and internet bulletin board & $16(29.6 \%)$ & $19(17.4 \%)$ & $24(11.2 \%)$ & $27(8.7 \%)$ & $10(5.7 \%)$ & $\begin{aligned} \chi^{2} & =30.18 \\
P & <0.001\end{aligned}$ \\
\hline Social networking services & $20(37.0 \%)$ & $25(22.9 \%)$ & $46(21.4 \%)$ & $52(16.7 \%)$ & $23(13.1 \%)$ & $\begin{aligned} \chi^{2} & =18.09, \\
\boldsymbol{P} & =0.001\end{aligned}$ \\
\hline Online game & $37(68.5 \%)$ & $73(67.0 \%)$ & $116(54.0 \%)$ & $140(45.0 \%)$ & $71(40.6 \%)$ & $\begin{aligned} \chi^{2} & =30.51, \\
P & <0.001\end{aligned}$ \\
\hline Movie and music & $44(81.5 \%)$ & $90(82.6 \%)$ & $171(79.5 \%)$ & $235(75.6 \%)$ & $126(72.0 \%)$ & $\begin{array}{l}\chi^{2}=6.15 \\
P=0.188\end{array}$ \\
\hline Shopping and auction & $16(29.6 \%)$ & $23(21.1 \%)$ & $37(17.2 \%)$ & $37(11.9 \%)$ & $21(12.0 \%)$ & $\begin{aligned} \chi^{2} & =16.03, \\
\boldsymbol{P} & =0.003\end{aligned}$ \\
\hline Others & $10(18.5 \%)$ & $14(12.8 \%)$ & $25(11.6 \%)$ & $23(7.4 \%)$ & $8(4.6 \%)$ & $\begin{aligned} \chi^{2} & =14.48 \\
P & =0.006\end{aligned}$ \\
\hline Females & $(N=31)$ & $(N=119)$ & $(N=212)$ & $(N=327)$ & $(N=222)$ & \\
\hline Information and news searching & $26(83.9 \%)$ & $84(70.6 \%)$ & $146(68.9 \%)$ & $207(63.3 \%)$ & $137(61.7 \%)$ & $\begin{array}{l}\chi^{2}=9.16 \\
P=0.057\end{array}$ \\
\hline $\begin{array}{l}\text { E-mail, chat, and internet } \\
\text { telephone }\end{array}$ & $26(83.9 \%)$ & $90(75.6 \%)$ & $161(75.9 \%)$ & $242(74.0 \%)$ & $151(68.0 \%)$ & $\begin{array}{l}\chi^{2}=6.11 \\
P=0.191\end{array}$ \\
\hline Blog and internet bulletin board & $10(32.3 \%)$ & $15(12.6 \%)$ & $14(6.6 \%)$ & $32(9.8 \%)$ & $11(5.0 \%)$ & $\begin{aligned} \chi^{2} & =28.53 \\
P & <0.001\end{aligned}$ \\
\hline Social networking services & $13(41.9 \%)$ & $54(45.4 \%)$ & $78(36.8 \%)$ & $114(34.9 \%)$ & $63(28.4 \%)$ & $\begin{aligned} \chi^{2} & =10.77 \\
P & =0.029\end{aligned}$ \\
\hline Online game & $13(41.9 \%)$ & $39(32.8 \%)$ & $51(24.1 \%)$ & $69(21.1 \%)$ & $28(12.6 \%)$ & $\begin{aligned} \chi^{2} & =27.35, \\
\boldsymbol{P} & <0.001\end{aligned}$ \\
\hline Movie and music & $27(87.1 \%)$ & $98(82.4 \%)$ & $170(80.2 \%)$ & $255(78.0 \%)$ & $169(76.1 \%)$ & $\begin{array}{l}\chi^{2}=3.51 \\
P=0.476\end{array}$ \\
\hline Shopping and auction & $11(35.5 \%)$ & $31(26.1 \%)$ & $30(14.2 \%)$ & $39(11.9 \%)$ & $17(7.7 \%)$ & $\begin{aligned} \chi^{2} & =34.72 \\
P & <0.001\end{aligned}$ \\
\hline Others & $7(22.6 \%)$ & $16(13.4 \%)$ & $19(9.0 \%)$ & $36(11.0 \%)$ & $13(5.9 \%)$ & $\begin{aligned} \chi^{2} & =11.89 \\
P & =0.018\end{aligned}$ \\
\hline
\end{tabular}

\section{Relationship between PIU and smartphone use}

Smartphones are known to be addictive Internet devices because of their portability and operability than other devices. Kawabe et al. (2016) reported that accessibility to smartphones was an important risk factor for IA. Screening tests for smartphone addiction have also been developed (Kim, Lee, Lee, Nam, \& Chung, 2014; Kwon et al., 2013). It has been reported that females display a significantly increased risk for smartphone addiction compared to males (Choi et al., 2015; Haug et al., 2015). In our study, we found smartphone ownership was significantly associated with higher risk for PIU compared with no ownership in both the total population and female subjects, but not in male subjects. Because many students already possess smartphone, parents should be encouraged to provide them the opportunity to be educated about appropriate smartphone usage.

\section{Relationship between PIU and type of Internet services}

Previous studies revealed that using "Online games" (Mihara et al., 2016; Tsitsika et al., 2014, "SNS” (Mihara et al., 2016; Tsitsika et al., 2014), and "Blog and bulletin board" (Mihara et al., 2016) were associated with an increased risk for IA. In our study, both male and female subjects who were younger at initial weekly Internet use tended to use many types of Internet services including those related to PIU. Adolescents who were younger at initial weekly Internet use tended to prefer more addictive Internet content. This group of subjects was able to use more addictive Internet content by using Internet for a prolonged period of time. The reason for this relationship between younger at initial customary Internet use and using more addictive Internet services was unclear in this study, and should be addressed in future investigations.

\section{Relationship between PIU and age at initial habitual Internet use}

Associations between age at initial Internet use and IA have been previously reported (Aktepe et al., 2013; Kamal \& Mosallem, 2013; Koyuncu et al., 2014; Lee et al., 2014; Ni et al., 2009; Tsitsika et al., 2014). For example, Lee et al. (2014) reported that $4.1 \%, 2.6 \%$, and $1.8 \%$ of participants, whose age at initial Internet use was younger than $7,8-10$, and 11 years or older, respectively, had suspected IA (YIAT 
Male

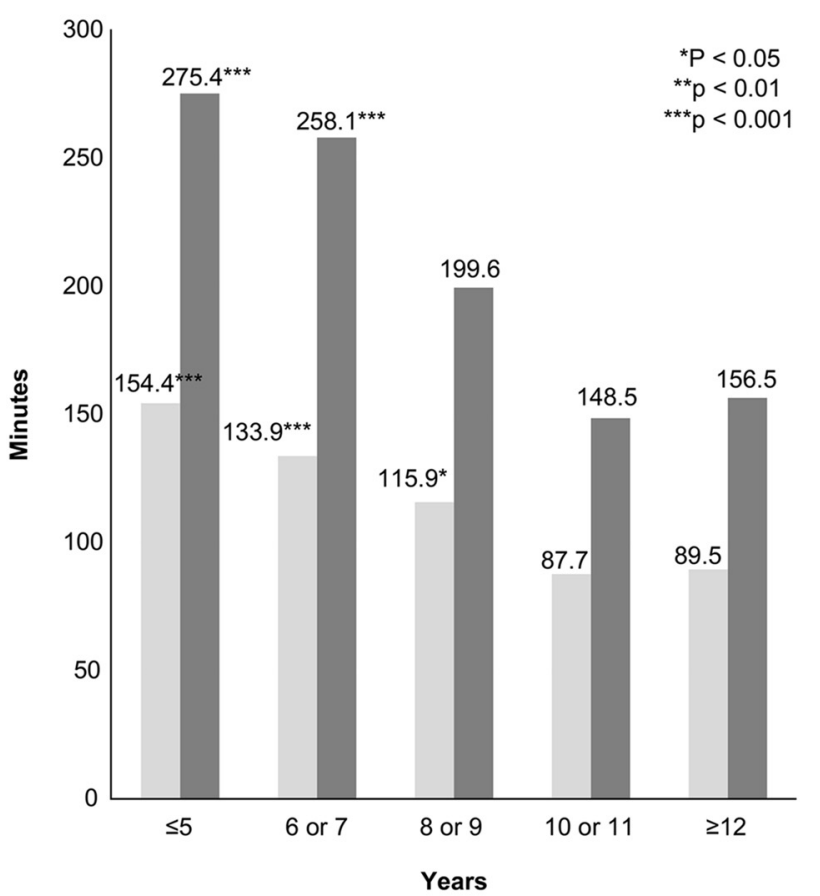

Female

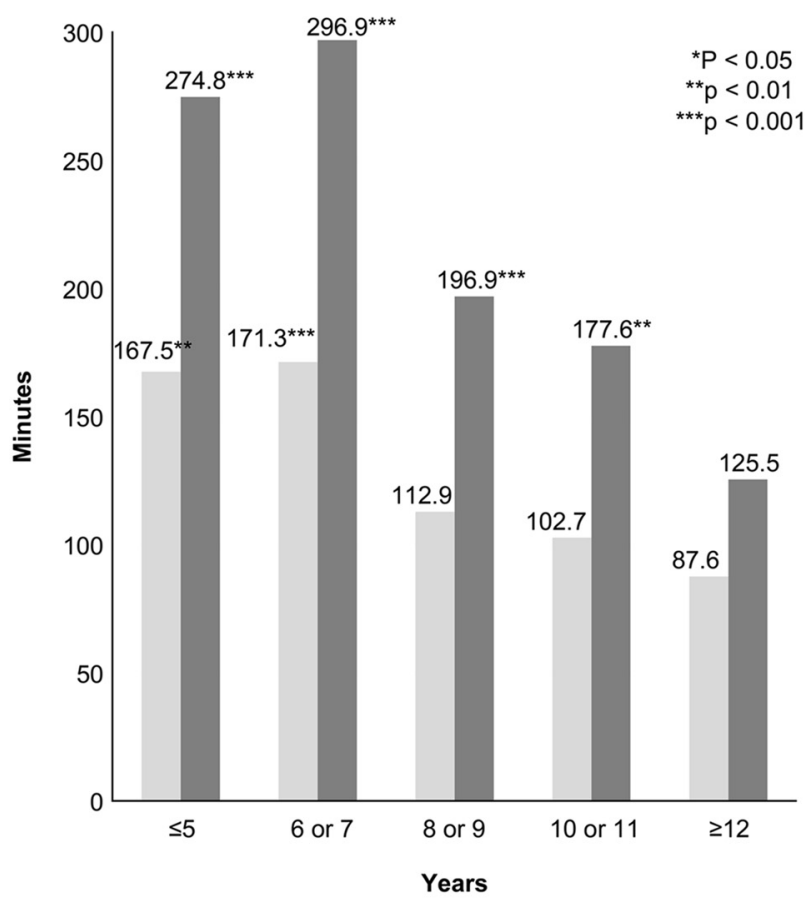

$\square$ Average duration of daily internet minutes on holidays

Figure 1. Average duration in minutes of daily Internet use on weekdays and holidays by age at initial weekly Internet use

Male

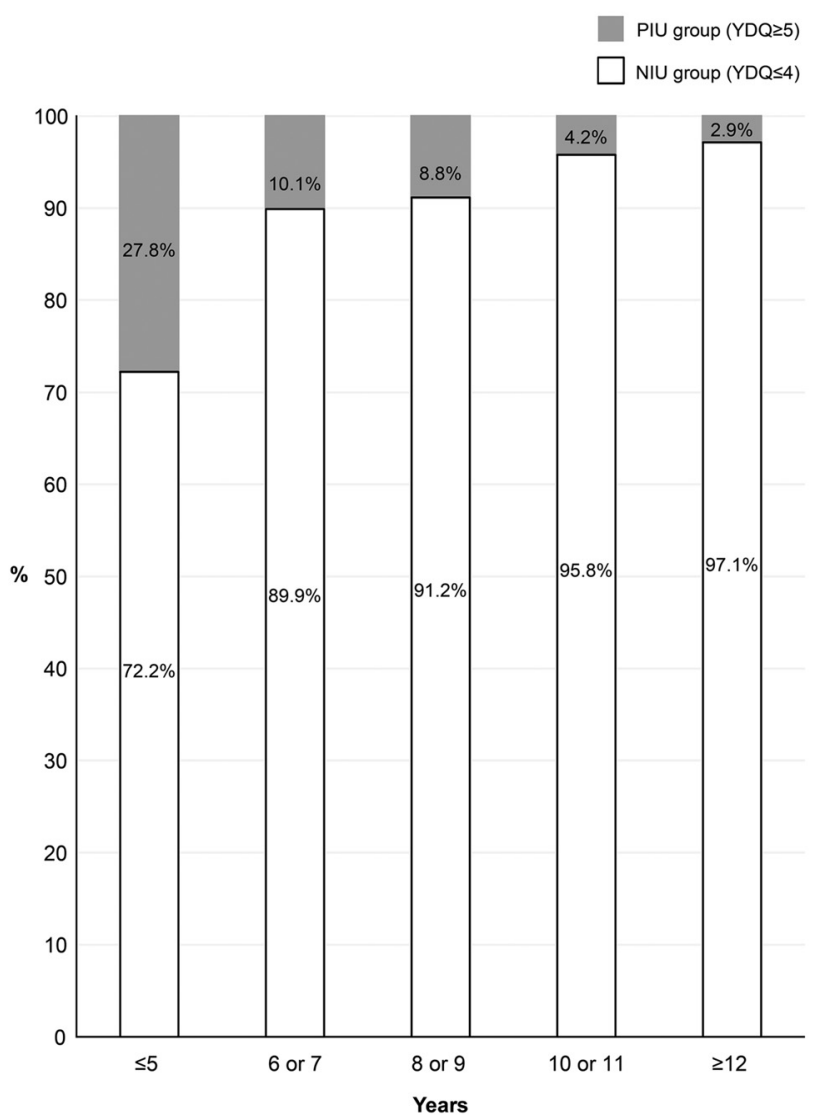

Female

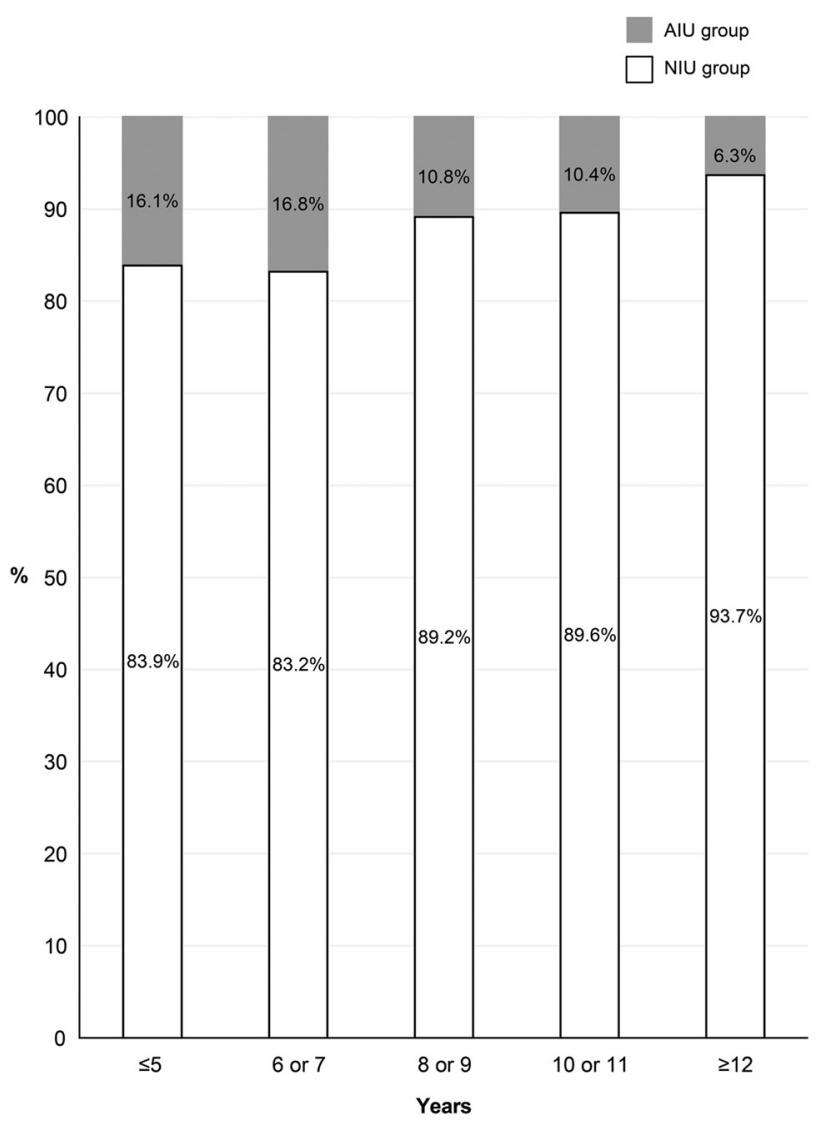

Figure 2. Young's Diagnostic Questionnaire (YDQ) score by age at initial weekly Internet use 
Table 5. Associations between gender, school grade, age at initial weekly Internet use, ownership of private portable phone, family rules regarding Internet use, and the risks of problematic Internet use (PIU: YDQ ${ }^{\mathrm{a}}$ ) score $\geq 5$ points

\begin{tabular}{|c|c|c|c|c|c|c|c|c|c|}
\hline & \multicolumn{3}{|c|}{ Total } & \multicolumn{3}{|c|}{ Males } & \multicolumn{3}{|c|}{ Females } \\
\hline & Adjusted OR & $95 \% \mathrm{CI}$ & $\mathrm{p}$-value & Adjusted OR & $95 \% \mathrm{CI}$ & $P$-value & Adjusted OR & $95 \% \mathrm{CI}$ & $P$-value \\
\hline \multicolumn{10}{|l|}{ Gender } \\
\hline Male & Reference & & & & & & & & \\
\hline Female & 1.656 & $1.175-2.334$ & 0.004 & & & & & & \\
\hline \multicolumn{10}{|l|}{ School Grade } \\
\hline 7th & Reference & & & Reference & & & Reference & & \\
\hline 8th & 1.748 & $1.145-2.669$ & 0.01 & 1.805 & $0.918-3.549$ & 0.087 & 1.769 & $1.024-3.058$ & 0.041 \\
\hline 9th & 1.980 & $1.285-3.052$ & 0.002 & 2.107 & $1.067-4.161$ & 0.032 & 1.959 & $1.114-3.447$ & 0.020 \\
\hline \multicolumn{10}{|c|}{ Age at initial weekly Internet use } \\
\hline $12 \leq$ & Reference & & & Reference & & & Reference & & \\
\hline $10-11$ & 1.857 & $1.064-3.242$ & 0.03 & 1.757 & $0.608-5.079$ & 0.298 & 1.943 & $1.004-3.760$ & 0.048 \\
\hline $8-9$ & 2.596 & $1.467-4.595$ & 0.001 & 3.913 & $1.412-10.847$ & 0.009 & 2.058 & $1.014-4.177$ & 0.046 \\
\hline $6-7$ & 3.633 & $1.977-6.674$ & $<0.001$ & 4.481 & $1.488-13.497$ & 0.008 & 3.328 & $1.589-6.969$ & 0.001 \\
\hline$\leq 5$ & 7.422 & $3.691-14.923$ & $<0.001$ & 14.955 & $5.053-44.260$ & $<0.001$ & 2.977 & $0.975-9.087$ & 0.055 \\
\hline \multicolumn{10}{|c|}{ Smartphone ownership } \\
\hline None & Reference & & & Reference & & & Reference & & \\
\hline Smartphone & 4.083 & $1.771-9.416$ & 0.001 & 1.859 & $0.644-5.365$ & 0.251 & 8.535 & $2.076-35.625$ & 0.003 \\
\hline \multicolumn{10}{|c|}{ Family rules regarding Internet use } \\
\hline No & Reference & & & Reference & & & Reference & & \\
\hline Yes & 0.746 & $0.671-1.331$ & 0.945 & 0.976 & $0.558-1.677$ & 0.929 & 0.949 & $0.605-1.484$ & 0.820 \\
\hline
\end{tabular}

${ }^{a}$ YDQ: Young's Diagnostic Questionnaire.

$\geq 70$ ), in a Korean middle school survey. Conversely, Malak, Khalifeh, and Shuhaiber (2017) reported that age at first Internet use was not significantly associated with the future risk of IA (YIAT $\geq 50$ ). It must be acknowledged that parents find it difficult to prevent their children from occasionally using the Internet in recent years, largely due to the rampant use of Internet-based devices at homes.

Almost all individuals with IA spend considerable lengths of time on Internet activities; IA is strongly associated with Internet overuse (Aktepe et al., 2013; Koyuncu et al., 2014; Mihara et al., 2016). The onset of IA was assumed to be associated with an environment in which the Internet is used for considerable lengths of time. Since children are unable to do so without the consent and oversight of parents and other adults who prepare the Internet environment for them, IA may not be necessarily a result of children merely using the Internet, but with the active participation of their guardians as well.

We hypothesized that the initial habitual use of the Internet might have a stronger association with IA than initial use of the Internet. It may be possible for parents to prevent their children from habitual use of the Internet. However, a relationship between the risk of IA and habitual Internet use in early childhood was not borne out in previous studies.

Our survey revealed that the risk of PIU was positively associated with a younger age at initial weekly Internet use. In particular, initial weekly Internet use before the age of five in boys was associated with a significantly increased risk of PIU, with an odds ratio of 14.955 compared with initial weekly Internet use after 12 years of age. In addition, our results showed that the average duration of daily Internet time and the utilization rate of each Internet services increased with younger age at initial weekly Internet use.
These results confirmed the relationship between PIU and age at initial weekly Internet use.

While obvious links between IA and Internet use have been made, the previous surveys were unable to conclude an association between IA and the duration of Internet use. For example, Ko et al. (2009) reported that using the Internet for more than four years does not significantly predict the risk of future IA, whereas, Kormas, Critselis, Janikian, Kafetzis, and Tsitsika (2011) reported that more than 12 months of Internet use was significantly related to IA.

The IA prevalence rate in adults tends to be lower than the rate in youth. For example, Park, Jeon, Bae, Seong, and Hong (2017) reported that the prevalence rate of IA (YDQ $\geq 5$ ) was $1.0 \%$ in a survey of adults. Currently, although most adults use the Internet, this was not available to them in their childhood since widespread use of the Internet began only two decades ago. These results suggest that IA may be more closely related to the age at initial habitual use rather than the number of years of Internet use.

Although adults tend to focus on Internet use in children, emphasis must be placed on the possibility of children's future IA onset. In addition, children who have already used the Internet at an early age must be monitored against future IA onset. Overall, our study throws support for longitudinal IA-preventive education from an early stage; moreover, prevention based on these risk factors should also target parents who can inculcate appropriate use of the Internet in children, starting from infancy.

\section{Limitations}

This study has several limitations. First, our assessment was based solely on self-reported data; objective viewpoints (e.g., those of parents or teachers) were lacking. Further, since 
students' childhood memories may not be accurate, we assumed that the subjects might be able to remember their first customary and habitual Internet use rather than initial use. Second, because our study design was cross-sectional, a cause-effect relationship could not be established, which would have been possible with longitudinal studies. Third, all participants were enrolled in public junior high schools in a city area. Thus, whether our findings are applicable to privateschool students and adolescents living in rural areas is unclear. Fourth, certain PIU risk factors (e.g., attention deficit hyperactivity symptoms, family function, socioeconomic status etc.)) were not considered in our study due to the nature of the questionnaire. Future studies should address these concerns.

\section{CONCLUSIONS}

Junior high school students who were younger at initial weekly Internet use tended to have PIU and to spend more time on Internet activities. In particular, initial weekly Internet use before the age of five in boys was associated with a significantly increased risk of PIU, with an OR of 14.955, compared with initial weekly Internet use after the age of 12 . Smartphone ownership significantly increased the risk of PIU compared with no ownership among the total population and among girls. Longitudinal IA preventive education from an early stage is necessary, and prevention based on these risk factors should also target parents who can inculcate appropriate use of the Internet in children, starting from infancy.

Funding sources: This study was supported by the Japan Ministry of Education and Culture, Sport Science and Technology Addiction Preventive Education Promotion project grant.

Author's contribution: All the authors contributed to the design of this study. H. N. performed the survey. H. N. conducted IA preventive lectures in each school after this survey. H. N. and S. H. performed the statistical analysis. H. N. wrote the first draft of this manuscript, and all the authors contributed to and approved the final manuscript.

Conflict of interest: All the authors declare no conflicts of interest in this study.

Acknowledgments: We are grateful to the students, teachers, and staffs of the A city Board of Education and the guardians who participated in and cooperated with the survey and intervention. The authors would like to thank Enago (www. enago.jp) for the English language review.

\section{REFERENCES}

Aktepe, E., Olgaç-Dündar, N., Soyöz, Ö., \& Sönmez, Y. (2013). Possible internet addiction in high school students in the city center of isparta and associated factors: A cross-sectional study. The Turkish Journal of Pediatrics, 55(4), 417-425.

Baggio, S., Starcevic, V., Studer, J., Simon, O., Gainsbury, S. M., Gmel, G., et al. (2018). Technology-mediated behaviors constitute a spectrum of related yet distinct conditions: A network perspective. Psychology of Addictive Behaviors, 32(5), 564-572.

Beard, K. W., \& Wolf, E. M. (2001). Modification in the proposed diagnostic criteria for internet addiction. CyberPsychology and Behavior, 4(3), 377-383.

Cabinet office government of Japan. (2017a). Survey on the internet usage environment for young children 2017. https://www8.cao. go.jp/youth/youth-harm/chousa/net-jittai_child.html.

Cabinet office government of Japan. (2017b). Survey on the Internet environment of young people 2017. https://www8.cao.go.jp/ youth/youth-harm/chousa/h29/net-jittai/pdf-index.html.

Cheng, C., \& Li, A. Y. (2014). Internet addiction prevalence and quality of (real) life: A meta-analysis of 31 nations across seven world regions. Cyberpsychology Behavior and Social Networking, 17(12), 755-760.

Choi, S. W., Kim, D. J., Choi, J. S., Ahn, H., Choi, E. J., Song, W. Y., et al. (2015). Comparison of risk and protective factors associated with smartphone addiction and internet addiction. Journal of Behavioral Addiction, 4(4), 308-314.

Choi, K., Son, H., Park, M., Han, J., Kim, K., Lee, B., et al. (2009). Internet overuse and excessive daytime sleepiness in adolescents. Psychiatry and Clinical Neurosciences, 63(4), 455462.

Cho, S. M., Sung, M. J., Shin, K. M., Lim, K. Y., \& Shin, Y. M. (2013). Does psychopathology in childhood predict internet addiction in male adolescents? Child Psychiatry and Human Development, 44(4), 549-555.

Critselis, E., Janikina, M., Paleomilitou, N., Oikonomou, D., Kassinopoulos, M., Kormas, G., et al. (2013). Internet gambling is a predictive factor of internet addictive behavior among cypriot adolescents. Journal of Behavioral Addiction, 2(4), 224-230.

Grant, B. F., \& Dawson, D. A. (1997). Age at onset of alcohol use and its association with DSM-IV alcohol abuse and dependence: Results from the National Longitudinal Alcohol Epidemiologic Survey. Journal of Substance Abuse, 9, 103110.

Hao, J., Oh, J., Subramanian, S. V., Kim, Y., \& Kawachi, I. (2014). Addictive internet use among Korean adolescents: A national survey. PloS One, 9(2), e87819.

Haug, S., Castro, R. P., Kwon, M., Filler, A., Kowatsch, T., \& Schaub, M. P., (2015). Smartphone use and smartphone addiction among young people in Switzerland. Journal of Behavioral Addiction, 4(4), 308-314.

Jang, K. S., Hwang, S. Y., \& Choi, J. Y. (2008). Internet addiction and psychiatric symptoms among Korean adolescents. Journal of School Health, 78(3), 165-171.

Japan Ministry of Internal Affairs. (2001). Communications usage trend survey 2001. https://www.soumu.go.jp/johotsusintokei/ statistics/data/020521_1.pdf.

Japan Ministry of Internal Affairs. (2017). Communications usage trend survey 2017. https://www.soumu.go.jp/johotsusintokei/ statistics/data/180525_1.pdf. 
Kamal, N. N., \& Mosallem, F. A. (2013). Determinants of problematic Internet use among El-Minia high school students, Egypt. International Journal of Preventive Medicine, 4(12), 1429-1437.

Kawabe, K., Horiuchi, F., Ochi, M., Oka, Y. \& Ueno, S. (2016). Internet addiction: Prevalence and relation with mental states in adolescents. Psychiatry and Clinical Neurosciences, 70(9), $455-462$.

Kim, D., Lee, Y., Lee, J., Nam, J. K., \& Chung, Y. (2014). Development of Korean smartphone addiction proneness scale for youth. PloS One, 9, e97920. https://doi.org/10.1371/ journal.pone.0097920.

Ko, C. H., Yen, J. Y., Chen, C. S., Yeh, Y. C., \& Yen, C. F. (2009). Predictive values of psychiatric symptoms for internet addiction in adolescents: A 2-year prospective study. Archives of Pediatrics and Adolescent Medicine, 163(10), 937-943.

Ko, C. H., Yen, J. Y., \& Yen, C. F. (2007). Factors predictive for incidence and remission of internet addiction in young adolescents: A prospective study. CyberPsychology and Behavior, 10(4), 545-551.

Korkmaz, M., \& Kiran-Esen, B. (2012). The effects of peer-training about secure internet use on adolescents. Turkish Psychological Counseling and Guidance Journal, 4, 180-187.

Kormas, G., Critselis, E., Janikian., M., Kafetzis, D., \& Tsitsika, A. (2011). Risk factors and psychosocial characteristics of potential problematic and problematic internet use among adolescents: A cross-sectional study. BMC Public Health, 11, 595. https://doi. org/10.11186/1471-2458-11-595.

Koyuncu, T., Unsal, A., \& Arslantas, D. (2014). Assessment of internet addiction and loneliness in secondary and high school students. Journal of the Pakistan Medical Association, 64(9), 998-1002.

Kuss, D. J., van-Rooij, A. J., Shorter, G. W., Griffiths, M. D., \& van-de Mheen, D. (2013). Internet addiction in adolescents: Prevalence and risk factors. Computers in Human Behavior, 29(5), 1987-1996.

Kwon, M., Lee, J. Y., Won, W. Y., Park, J. W., Min, J. A., Hahn, C., et al. (2013). Development and validation of a smartphone addiction scale (SAS). PloS One, 8(2), e56936.

Lanza, S. T. \& Vasilenko, S. A. (2015). New methods shed light on age of onset as a risk factor for nicotine dependence. Addictive Behavior, 50, 161-164. https://doi.org/10.1016/j.addbeh.2015.06.024.

Lee, C. S., \& Kwame, M. (2015). Socioeconomic and geographic inequalities of internet addiction in Korean adolescents. Psychiatry Investigation, 12(4), 559-562.

Lee, J. Y., Shin, K. M., Cho, S. M., \& Shin, Y. M. (2014). Psychosocial risk factors associated with internet addiction in Korea. Psychiatry Investigation, 11(4), 380-386.

de Leeuw, J. R., de Bruijn, M., de Weert-van Oene G. H., \& Schrijvers, A. J. (2010). Internet and game behaviour at a secondary school and a newly developed health promotion programme: A prospective study. BMC Public Health, 10, 544. https://doi.org/10.1186/1471-2458-10-544.

Mak, K. K., Lai, C. M., Watanabe, H., Kim, D. I., Bahar, N., Ramos, M., et al. (2014). Epidemiology of internet behaviors and addiction among adolescents in six Asian countries. Cyberpsychology Behavior and Social Networking, 17(11), $720-$ 728.
Malak, M. Z., Khalifeh, A. H., \& Shuhaiber, A. H. (2017). Prevalence of internet addiction and associated risk factors in Jordanian school students. Computers in Human Behavior, 70, 556-563.

Mihara, S., Osaki, Y., Nakayama, H., Sakuma, H., Ikeda, M., Itani, O., et al. (2016). Internet use and internet use disorder among adolescents in Japan: A nationwide representative survey. Addictive Behaviors Reports, 4, 58-64. https://doi.org/10.1016/j. abrep.2016.10.001.

Ni, X., Yan, H., Chen, S., \& Liu, Z. (2009). Factors influencing internet addiction in a sample of freshmen university students in China. CyberPsychology and Behavior, 12(3), 327-330.

Ohida, T., Osaki, Y., Kaneita, Y., Suzuki, K., Higuchi, S., Kanda, H., et al. (2014). Health labor and welfare research grant, Survey on the health problem and lifestyle of adolescents, summary report in 2013.

Park, S., Jeon, H. J., Bae, J. N., Seong, S. J., \& Hong, J. P. (2017). Prevalence and psychiatric comorbidities of internet addiction in a nationwide sample of Korean adults. Psychiatry Investigation, 14(6), 879-882.

Sakuma, H., Mihara, S., Nakayama, H., Miura, K., Kitayuguchi, T., Maezono, M., et al. (2017). Treatment with the Self-Discovery Camp (SDiC) improves internet gaming disorder. Addictive Behaviors, 64, 357-362. https://doi.org/10.1016/j.addbeh.2016. 06.013.

Starcevic, V., \& Aboujaoude, E. (2017). Internet addiction: Reappraisal of an increasingly inadequate concept. CNS Spectrums, 22, 7-13. https://doi.org/10.1017/S1092852915000863.

Stavropoulos, V., Alexandraki, K., \& Motti-Stefanidi, F. (2013). Recognizing internet addiction: Prevalence and relationship to academic achievement in adolescents enrolled in urban and rural Greek high schools. Journal Of Adolescence, 36(3), 565576.

Sung, J., Lee, J., Noh, H. M., Park, Y. S., \& Ahn, E. J. (2013). Associations between the risk of internet addiction and problem behaviors among Korean adolescents. Korean Journal of Family Medicine, 34(2), 115-122.

Tang, J., Zhang, Y., Li, Y., Liu, L., Liu, X., Zeng, H., et al. (2014). Clinical characteristics and diagnostic confirmation of internet addiction in secondary school students in Wuhan, China. Psychiatry and Clinical Neurosciences, 68(6), 471-478.

Tsitsika, A., Janikian, M., Schoenmakers, T. M., Tzavela, E. C., Olafsson, K., Wojcik, S., et al. (2014). Internet addictive behavior in adolescence: A cross-sectional study in seven European countries. Cyberpsychology Behavior and Social Networking, 17(8), 528-535.

Wang, H., Zhou, X., Lu, C., Wu, J., Deng, X., \& Hong, L. (2011). Problematic internet use in high school students in Guangdong province, China. PLoS One, 6, e19660. https://doi.org/10.1371/ journal.pone.0019660.

Yen, J. Y., Ko, C. H., Yen, C. F., Chen, S. H., Chung, W. L., \& Chen, C. C. (2008). Psychiatric symptoms in adolescents with internet addiction: Comparison with substance use. Psychiatry and Clinical Neurosciences, 62, 9-16. https://doi.org/10.1111/j.14401819.2007.01770.x.

Young, K. S. (1996). Internet addiction: The emergence of a new clinical disorder. CyberPsychology and Behavior, 1(3), 237244. 
Young, K. S. (1998). Caught in the Net: How to recognize the signs of internet addiction and a winning strategy for recovery. New York, NY: John Wiley \& Sons.
Young, K. S. (2009). Internet addiction: Diagnosis and treatment considerations. Journal of Contemporary Psychotherapy, 39, 241-246.

This is an open-access article distributed under the terms of the Creative Commons Attribution-NonCommercial 4.0 International License (https://creativecommons.org/ licenses/by-nc/4.0/), which permits unrestricted use, distribution, and reproduction in any medium for non-commercial purposes, provided the original author and source are credited, a link to the CC License is provided, and changes - if any - are indicated. 